\title{
Avaliação microbiológica e bromatológica da silagem ácida obtida de resíduos da indústria de filetagem de tilápia do Nilo (Oreochromis niloticus) ${ }^{1}$
}

\section{Microbiological and bromatologic evaluation of acid silage gotten from Nile tilapia (Oreochromis niloticus) filletage industry residues}

\author{
Wilson Rogério Boscolo ${ }^{2 *}$; Ângela Maria dos Santos ${ }^{3}$; Cleide Viviane Buzanello \\ Martins $^{4}$; Aldi Feiden ${ }^{5}$; Fábio Bittencourt ${ }^{6}$; Arcangelo Augusto Signor ${ }^{7}$
}

\section{Resumo}

O experimento constituiu em avaliar a silagem ácida preparada a partir dos resíduos de filetagem de tilápia (Oreochromis niloticus). Esta silagem foi preparada em uma indústria de filetagem mediante a moagem dos resíduos e adição de 5\% de ácido acético e estocagem por um período de até 201 dias. Foram avaliadas silagens estocadas por 7, 12, 22, 27, 41, 48, 61, 75, 84, 91, 96, 110, 140, 151, 181, 187 e 201 dias. Foram realizadas análises bromatológicas de proteína bruta (PB), extrato etéreo (EE), umidade (UM), cinzas (CZ) e análises microbiológicas de Salmonella, coliformes totais, fecais e Escherichia coli das silagens estocadas por 7, 91 e 201 dias. $\mathrm{O} \mathrm{pH}$ foi avaliado em todos os períodos estocados. Não foram observadas diferenças $(\mathrm{P}>0,05)$ nos teores de $\mathrm{PB}, \mathrm{EE}, \mathrm{UM}$ e CZ. Observou-se um aumento linear no $\mathrm{pH}$, estabilizando-se em platô em 4,74. Com relação à análise microbiológica não foram constatadas a presença de Salmonella, coliformes totais, fecais e E. coli. Concluiu-se que a silagem ácida obtida a partir de resíduos de filetagem de tilápias produzidas com a utilização de 5\% de ácido acético pode ser armazenada durante 201 dias sem que haja a proliferação de Salmonella e coliformes totais fecais.

Palavras-chave: Resíduos de filetagem, estocagem de silagem

\begin{abstract}
The experiment constituted in evaluating the acid silage prepared from Nile tilapia (Oreochromis niloticus) filletage industry residues. This silage was prepared in a filetage industry through the residues milling and $5 \%$ of ascetic acid addition and stock piling in a period up to until 201 days. Storaged silages in a period of $7,12,22,27,41,48,61,75,84,91,96,110,140,151,181,187$ and 201dias were evaluated. Bromatologics analyses of rude protein(PB), etereal extract (EE), humidity (UM), ashes (CZ) and microbiological analyses of Salmonella, total coliforms, faecals and Escherichia coli of the storaged silages in a period of 7,91 and 201 days were realized. The $\mathrm{pH}$ was evaluated in all the storaged periods. Differences $(\mathrm{P}>0.05)$ in the substance of $\mathrm{PB}, \mathrm{EE}, \mathrm{UM}$ and $\mathrm{CZ}$ were not observed. A linear increase in $\mathrm{PH}$ was observed, being stabilizing in plateau of 4.74. In relation to the microbiological analysis the presence of Salmonella, total coliforms, faecals and E. Coli were not found. Was concluded that the acid silage gotten from tilapia filetage residues produced with the use of $5 \%$ ascetic acid can be stored during 201 days without having Salmonella, total coliforms and faecals proliferation.
\end{abstract}

Key words: Filletage residues, silage stock piling

\footnotetext{
1 Monografia de Especialização em Engenharia de Alimentos

2 Zootecnista, Professor Adjunto da UNIOESTE, Campus Toledo/Paraná, E- mail: wrboscolo@unioeste.br

3 Especialista em Engenharia de Alimentos, UNIOESTE- Campus Toledo, E-mail: angisanti@bol.com.br

4 Bióloga, Professora Adjunta da UNIOESTE, Campus de Toledo/Paraná.

Agrônomo, Professor Adjunto da UNIOESTE, Campus Toledo/Paraná - E- mail: aldi@unioeste.br

6 Zootecnista, Mestre em Zootecnia, Doutorando em Aquicultura, CAUNESP/UNESP - Jaboticabal - SP.

7 Engenheiro de Pesca, Mestre em Zootecnia, Doutorando em Zootecnia, UEM - Maringá - PR.

* Autor para correspondência
} 


\section{Introdução}

A necessidade do aproveitamento integral dos subprodutos gerados pelo cultivo de peixes é crescente, principalmente devido a porcentagem dos resíduos após a filetagem. Estes resíduos se não utilizados podem gerar problemas de ordem econômica e ambiental para o abatedouro de peixes (MACHADO, 1998). Como resíduos do processamento de peixes considera-se a cabeça, nadadeiras, pele e vísceras que, dependendo da espécie, pode chegar a $66 \%$ em relação ao seu peso total (CONTRERAS-GUZMÁN, 1994; SOUZA; MACEDO-VIEGAS; KRONKA, 1999), mostrando que mais de $2 / 3$ da captura não é utilizada como alimento humano (REBECA; PEÑA-VERA; DÍAZCASTAÑEDA, 1991).

A transformação dos resíduos dos frigoríficos de pescados em produtos para a alimentação animal seria mais uma opção de renda para as indústrias aumentando sua lucratividade (BOSCOLO, 2003), caso contrário pode permanecer na própria planta industrial como um agente contaminante, pois o pescado apresenta rápida deterioração (SEIBEL; SOUZA-SOARES, 2003). A silagem é um produto liquefeito obtido a partir do pescado inteiro impróprio para consumo humano ou de resíduos de beneficiamento dos mesmos, pois a liquefação é realizada pelas enzimas do próprio pescado, sendo que esta taxa depende do frescor do mesmo e da temperatura do processo. O produto líquido pode ser obtido por outras vias, porém, as enzimas presentes após a moagem da massa são difundidas uniformemente e sua ação é favorecida pelo agente de acidez através do uso dos ácidos, estes também atuam inibindo a ação microbiana (TATTERSON; WINDSOR, 1974; OETTERER, 2002).

Segundo Kompiang (1981) a preservação da silagem pode ser por ação de ácidos (silagem química), fermentação microbiana induzida por carboidratos (silagem biológica) e ação natural de enzimas do pescado ou adicionadas (silagem enzimática).
A silagem de peixe pode ser produzida por peixe inteiro ou commaterial residual(BEERLI;LOGATO; BEERLI, 2002), a qual é utilizada atualmente para ração animal, como fonte de proteína, não devendo ser considerada como competidor da farinha de peixe, e sim como uma alternativa. A silagem é uma fonte de proteína de alta qualidade e de minerais e pode ser utilizada como suplemento na ração de vários animais, como peixes, suínos, ovelhas, gados e aves domésticas (HAARD et al., 1985). $\mathrm{Na}$ Escandinávia esse procedimento é comum na alimentação de animais e peixes dado seu valor nutritivo (MANIKADAVELU et al.,1992; DAS et al., 1993). No entanto, segundo Raa e Gilbert (1976) os produtos secundários da oxidação podem reagir com as proteínas e reduzir seu valor nutricional. Uma provável explicação é o fato dos aminoácidos livres serem derivados rapidamente da síntese protéica para a rota catabólica (ESPE; JAN RAA; NJAA, 1989).

Entre as vantagens da produção de silagem da farinha de peixe, pode se citar que o produto apresenta maior digestibilidade (HASSAN; HEATH, 1987), o processo é virtualmente independente da escala, a tecnologia é simples mesmo para produção em longa escala, o capital de custo é pequeno, os efluentes e odores são reduzidos, não é necessário armazenamento do produto refrigerado, o processo é rápido em climas tropicais e o produto pode ser utilizado de imediato (BEERLI; LOGATO; BEERLI, 2002).

Objetivou-se com este trabalho a avaliação microbiológica e bromatológica da silagem ácida obtida de resíduos da indústria de filetagem de tilápia do Nilo (Oreochromis niloticus) com inclusão de 5\% de ácido acético a fim de determinar a qualidade desta silagem estocada por um período de até 201 dias.

\section{Materiais e Métodos}

O experimento foi realizado nos laboratórios de Microbiologia e Tecnologia do Pescado da 
Universidade Estadual do Oeste do Paraná Campus Toledo/PR, em parceria com uma indústria de filetagem da região que forneceu a matéria-prima.

A matéria-prima se constituiu de resíduos de filetagem de tilápia, sendo esses cabeças, espinhas, nadadeiras e vísceras. Esses resíduos foram moídos e misturados de modo a obter uma massa homogênea. Posteriormente foi adicionado 5\% de ácido acético e estocado em galões plásticos de 100L por um período de até 201 dias. Para análise, foram coletadas amostras de três galões que permaneciam em uma indústria de filetagem da região por um período de $7,12,22,27,41,48,61,75,84,91,96,110,140$, $151,181,187$ e 201 dias de estocagem.

Foram realizadas análises microbiológicas de investigação de presença de Salmonella, coliformes totais e fecais e E. coli com metodologias de investigação adaptadas de Silva; Junqueira e Silveira, (1997) e as análises bromatológicas de proteína bruta $(\mathrm{PB})$, extrato etéreo $(\mathrm{EE})$, cinzas (CZ) e umidade (UM) foram realizadas segundo a metodologia de Silva (1990). A coleta das amostras foi realizada nos períodos de 7,91 e 201 dias de estocagem, para a análise foram coletadas amostras de três galões por período e analisadas em triplicata em Laboratório.

A determinação do $\mathrm{pH}$ foi realizada em três galões por períodos analisados $(7,12,22,27,41$, $48,61,75,84,91,96,110,140,151,181,187$ e 201 dias), sendo que o $\mathrm{pH}$ foi determinado diretamente na amostra através de aparelhos eletrônicos, marca HANNA, modelo, HI 9015.

Os dados obtidos foram submetidos a análise de variância ao nível de 5\% de probabilidade e em caso de diferenças utilizou-se análise de LRP (Linear Response Plateou) pelo programa estatístico SAEG (Sistema de Análise Estatística e Genética) (UNIVERSIDADE FEDERAL DE VIÇOSA, 1997).

\section{Resultados e Discussão}

Os resultados das análises de Salmonella, Coliformes Totais, Coliformes Fecais e E. coli estão apresentados na Tabela 1.

Tabela 1. Resultados das análises microbiológicas da silagem ácida de resíduos da indústria de filetagem de tilápias estocadas por diferentes períodos.

\begin{tabular}{lcccc}
\hline & \multicolumn{4}{c}{ Parâmetros Microbiológicos das silagens } \\
\cline { 2 - 5 } Dias* & Salmonella em 25 g & $\begin{array}{c}\text { Coliformes Totais } \\
\text { UFC**/g }\end{array}$ & $\begin{array}{c}\text { Coliformes Fecais } \\
\text { UFC }\end{array}$ & $\begin{array}{c}\text { E.coli } \\
\text { UFC }\end{array}$ \\
\hline 7 & Ausente & $<0,3$ & $<0,3$ & $<0,3$ \\
91 & Ausente & $<0,3$ & $<0,3$ & $<0,3$ \\
201 & Ausente & $<0,3$ & $<0,3$ & $<0,3$ \\
\hline
\end{tabular}

*análise realizadas em duplicata

* *UFC/ g: Unidades Formadoras de Colônias

Não foi observada a presença de Salmonella nas amostras de silagem analisadas, em $25 \mathrm{~g}$ de amostra, indicando que a quantidade de $5 \%$ de ácido acético adicionado na silagem, não permitiu o desenvolvimento de Salmonella. Segundo Ucci (2003) nos resíduos de tilápias trituradas sem adição de ácidos constatou-se a presença de Salmonella e Coliformes Fecais sendo de 2,4 x $10^{3} \mathrm{UFC} / \mathrm{g}$ de amostra, e já as mesmas amostras de silagens com adição de ácidos apresentaram ausência de Salmonella e Coliformes Fecais $(<3$ $\mathrm{UFC} / \mathrm{g})$, corroborando com os resultados do atual 
experimento. Estes microrganismos não existem originalmente no pescado, sendo introduzidos durante a manipulação ou por contado com águas contaminadas, mas sua presença constitui um grande problema de saúde pública devido ao seu caráter patogênico. A pesquisa para Salmonella é qualitativa, ou seja, presença ou ausência, nenhum alimento pode conter Salmonella em $25 \mathrm{~g}$ de amostra. Este resultado negativo para Salmonella representa boa qualidade microbiológica do manuseio adequado e eficiente, tanto na captura do pescado, quanto na filetagem (OGAWA; MAIA, 1999).

Menti et al. (2003), avaliando a presença de Salmonella em silagem ácida preparada a partir de tilápias inteiras descartadas na despesca (tamanho inferior ao comércio) com adição de 4\% de ácido sulfúrico, constataram que a utilização de ácidos em silagem elimina a Salmonella, pois o ácido assegura que o $\mathrm{pH}$ no final do processo seja inferior a 4,0. Ucci (2003), também não observou presença de Salmonella em silagens ácidas elaboradas com adição de ácido fosfórico, fórmico e sulfúrico em $4 \%$ ou adição de $2 \%$ ácido sulfúrico $+2 \%$ ácido fórmico para o período de 90 dias de estocagem. Menti et al. (2003); Ucci (2003) conseguiram obter em suas silagens valores de $\mathrm{pH}$ inferiores a 4,0 dificultando o crescimento de tais microrganismos.

Observou-se no experimento, através da análise de LRP (Linear Response Plateou), um aumento linear no $\mathrm{pH}$ estabilizando-se aos 75 dias com platô em 4,74 (pH), conforme Figura 1.

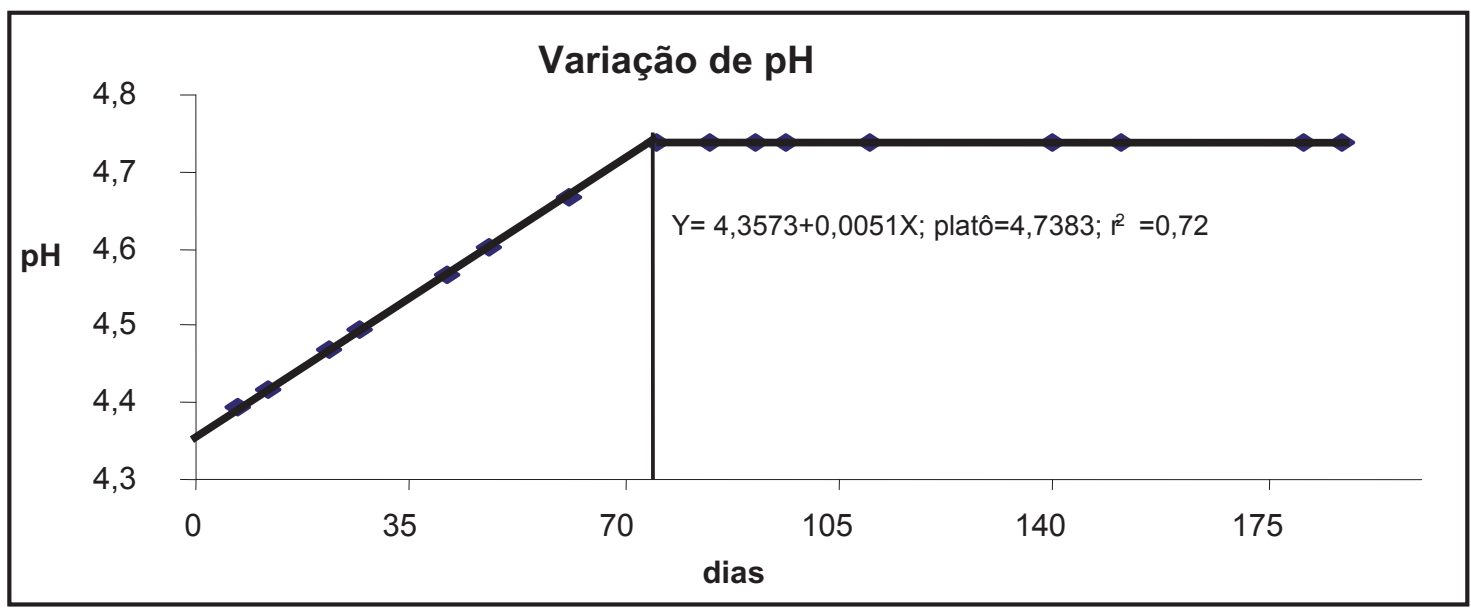

Figura 1. pH da silagem ácida de resíduos da indústria de filetagem de tilápias estocadas por diferentes períodos.

Vários autores tais como Rouvinen (1997), Lien, Phung e Ly (2000), evidenciaram a necessidade do valor do pH para a produção de silagem ser inferior a 4,5 para evitar a proliferação de Salmonella. Os resultados deste experimento apresentaram valores de $\mathrm{pH}$ superiores aos relatados pelos autores, porém, resultou em ausência de Salmonella e Coliformes Totais, Fecais e E. coli $<0,3 \mathrm{NMP} / \mathrm{g}$ da amostra.

A silagem biológica pode-se considerar um produto estável química e microbiologicamente.
Além disso, apresenta a vantagem de não haver a necessidade de neutralização antes da sua utilização no preparo de rações para alimentação animal. Dong et al. (1993), Kjos et al. (2000); Lien e Ly (2001) também não relataram a presença de microorganismos em silagem, demonstrando que outras formas podem ser utilizadas com eficiência na prevenção de microorganismos mantendo a qualidade do produto final. Ucci (2003) observou que para se neutralizar silagens com $\mathrm{pH}$ abaixo de 3 é necessário quantidades de cal superior a $5 \%$. 
Com isto eleva-se a quantidade de matéria mineral do produto e conseqüentemente de cálcio sendo que este fato pode trazer transtornos nutricionais aos animais (NATIONAL RESEARCH COUNCIL, 1993).
$\mathrm{Na}$ (Tabela 3), estão apresentados os valores médios de umidade (UM), cinzas (CZ), proteína bruta (PB) e extrato etéreo (EE) da silagem de resíduos da indústria de filetagem de tilápias.

Tabela 3. Valores médios das análises bromatológicas da silagem de resíduos da indústria de filetagem de tilápias.

\begin{tabular}{lcccc}
\hline \multirow{2}{*}{ Variáveis $(\%)^{1}$} & \multicolumn{3}{c}{ Dias de estocagem } & C.V.\% \\
\cline { 2 - 4 } & 7 & 91 & 201 & 5,71 \\
Umidade & 67,42 & 70,73 & 72,98 & 15,04 \\
Cinzas $^{2}$ & 6,57 & 5,91 & 5,77 & 15,40 \\
Proteína bruta $(\mathrm{PB})^{2}$ & 13,08 & 13,75 & 12,32 & 13,28 \\
Extrato etéreo $(\mathrm{EE})^{2}$ & 14,90 & 10,19 & 9,52 & \\
\hline
\end{tabular}

${ }^{1} \mathrm{P}>0,05$. $\quad{ }^{2}$ Dados na matéria natural.

Não foram observadas diferenças $(\mathrm{P}>0,05)$ nos parâmetros de umidade, matéria seca, cinzas e estrato etéreo em função do tempo de estocagem da silagem de resíduos da indústria de filetagem de tilápias nos diferentes períodos de estocagem.

O teor de matéria seca do atual experimento é inferior ao observado por Carvalho et al. (2006). Esta variação pode ser explicada pelo fato dos autores terem incluído $30 \%$ de farelo de trigo, visando diminuir a umidade e evitar a proliferação de microorganismos. Esta recomendação também foi evidenciada por Green; Wiseman e Cole (1998), que ressalta a utilização de alimentos secos (farelo de trigo, farelo de soja ou milho) na fabricação de ração para animais, pois estes ingredientes apresentam aproximadamente $88 \%$ de MS.

A silagem com alto teor de umidade, como observada neste trabalho, também pode ser utilizada em rações para cães, gatos, e peixes, através de sua incorporação através de banhos nos peletes de ração, com objetivo palatabilizante. Neste caso não seria necessário a sua desidratação (UCCI, 2003).

Os teores de proteína bruta da silagem encontram-se próximos aos observados por Ucci (2003) e Vidotti, Viegas e Carneiro (2003), em seu experimento com silagens ácidas obtidas a partir de resíduos da tilápia. Os teores de $\mathrm{PB}$ relatados por Carvalho et al. (2006), são superiores aos observados no presente trabalho, isto pode ser explicado pela adição de farelo de trigo na silagem, diminuindo a umidade e consequentemente aumentado a proteína. Porém, Boscolo (2003) relata que os teores de proteína da silagem são inferiores aos observados para a farinha obtida dos mesmos resíduos, sendo que esta diferença é explicada pelo processamento da farinha, pois ocorre a prensagem da matériaprima cozida retirando uma parte da gordura e concentrando a proteína.

A silagem apresentou grande quantidade de gordura em todos os períodos de estocagem $(7,91$ e 201 dias), isto se deve a constituição física da mesma, que é compreendida por grande quantidade de vísceras que é o principal local de depósito de gordura das tilápias (CONTRERAS-GUZMÁN, 1994). Valores semelhantes também foram observados por Ucci (2003), Oetterer (1994), no entanto, Carvalho et al. (2006) relatam ter observado resultados superiores aos do atual experimento. Esta variação nos resultados pode ser explicada pela variação na qualidade da matéria prima utilizada, principalmente quanto ao tamanho e época do ano, pois estas variáveis influenciam no depósito de gordura visceral. 
A quantidade de cinzas encontrada nas silagens em um período de 201 dias apresentou-se alta, cerca de $20 \%$. Isto se deve ao fato de a silagem ser constituída somente de resíduos, podendo-se observar que os minerais ficaram mais concentrados nestes resíduos. Resultados semelhantes foram observados por Boscolo (2003), avaliando o teor de cinzas da farinha de resíduos de tilápias que observou $18,75 \%$ de matéria mineral, teor este, próximo ao observado por Hardy (1996), Rostagno et al. (2000) em farinhas de peixes produzidas a partir de resíduos de pescado.

A utilização de resíduos para a elaboração de silagem ácida é uma forma de eliminar um problema ambiental que é o descarte destes resíduos, além de ser uma alternativa de utilização em rações animais.

\section{Conclusão}

Conclui-se que a silagem ácida de resíduos da indústria de filetagem de tilápia com adição de 5\% de acido acético pode ser estocada por 201 dias, sem apresentar proliferação de microrganismos.

\section{Referências}

BEERLI, E. L.; LOGATO, P. V. R.; BEERLI, K. M. C. Silagem ácida de resíduos de filetagem de trutas (Oncorhynchus mykiss). In: AQUICULTURA BRASIL 2002, SIMPÓSIO BRASILEIRO DE AQÜICULTURA SIMBRAQ, 12., 2002, Goiânia. Anais... Goiânia: UFG, 2002. p. 6. v. 1.

BOSCOLO, W. R. Farinha de resíduos da indústria de filetagem de tilápias na alimentação de tilápia do Nilo (Oreochromis niloticus). Maringá: Universidade Estadual de Maringá, Centro de Ciências Exatas, 2003.

CARVAlho, G. G. P.; PIRES, A. J. V.; VEloso, C. M.; SILVA, F. F.; CARVALHO, B. M. A. Silagem de resíduo de peixes em dietas para alevinos de tilápia-donilo. Revista Brasileira de Zootecnia, Viçosa, v. 35, n. 1, p. 126-130, 2006.

CONTRERAS-GUZMÁN, E. Bioquímicos de pescados e derivados. Jaboticabal, FUNEP, 1994. 409 p.
DAS, H. K.; HATTULA, M. T.; MYLLYMÄKI, O. M.; MÄLKKI, Y. Effects of formulation and processing variables on dry fish feeds pellets containing fish waste. Journal of Food and Science, Champaign, v. 61, p. 181187, 1993.

DONG, F. M.; FAIRGRIEVE, W. T.; SKONBERG, D. I.; RASCO, B. A.; Preparation and nutrient analyses of lactic acid bacterial ensiled salmon viscera. Aquaculture, Amsterdam, v. 109, n. 4, p. 351-366, 1993.

ESPE, M.; JAN RAA, J.; NJAA, L. R. Nutritional value of stored fish silage as a protein source for young rats. Journal of Science Food and Agriculture, New York, v. 49, n. 3, p. 259-70, 1989.

GREEN, S.; WISEMAN, J.; COLE, D. J. A. Examination of stability, and its effect on the nutritive value of fish silage in diets for growing pigs. Animal Feed Science and Technology, Amsterdan, v. 21, n. 1, p. 43-56, 1998.

HAARD, N. F.; KARIEL, N.; HERZBERG, G.; FELTHAM, L. A. W.; WINTER, K. Stabilization of protein and oil in fish silage for use as a ruminante feed suplement. Journal of Science Food and Agriculture, London, v. 36, n. 1, p. 229-241, 1985.

HARDY, R. W. Alternate protein sources for salmon and trout diets. Animal Feed Science Technology, Amsterdam, v. 59, n. 3, p. 71-80, 1996.

HASSAN, T. E.; HEATH, J. L. Chemical and nutritive characteristics of fish silage produced by biological fermentation. Biological-Wastes Working, France, v. 20, n. 3, p. 187-201, 1987.

KJOS, N. P.; HERSTAD, O.; OVERLAND, M.; SKREDE, A. Effects of dietaryfish silage and fish fat on growth performance and meat quality of broiler chicks. Canadian Journal of Animal Science, Ottawa, v. 80, n. 2, p. 625-632, 2000.

KOMPIANG, I. P. Fish silage, its prospect and future in Indonesia. Indonesian Agricultural Research \& Development Journal, Indonesia, v. 3, n. 1, p. 9-12, 1981.

LIEN, L.V.; LY, L.V. Replacing fish meal by fish silage in pig diet. In: WORKSHOP ON IMPROVED UTILIZATION OF BYPRODUCTS FOR ANIMAL FEEDING, 3., 2001, Vietnam. Anais... Vietnam: National Institute of Animal Husbandry, 2001. p. 14-23.

LIEN, L.V; PHUNG, N. T.; LY, L. V. Ensiled fish byproducts as a protein supplement for fattening pigs. In: WORKSHOP - SEMINAR "MAKING BETTER USE OF LOCAL FEED RESOURSES". SAREC, 2000. Proceedings... [S.1.]: UAF, 2000. 
MACHADO, T. M. Silagem biológica de pescado. Panorama da Aqüicultura, Rio de Janeiro, v. 8, n. 47, p. 30-32, 1998.

MANIKADAVELU, D.; NEETHISELVAN, J.; JAGATHEESAN, J.; SUNDARSANAM, K. Use of fermented ensilage based diet in enhancing the growth of common carp (Cyprinus carpio var. communis). Fishery Technology, Cochin, v. 29, n. 1, p. 111-113, 1992.

MENTI, M. M.; SIGNOR, A.; MARTINS, C. V. B.; BOSCOLO, W. R.; FEIDEN, A. Investigação de Salmonella na silagem de pescado de água doce. In: CONGRESSO BRASILEIRO DE ENGENHARIA DE PESCA, 13., 2003, Porto Seguro. Anais... Porto Seguro, 2003. p. 1110-1114.

NATIONAL RESEARCH COUNCIL - NRC. Nutrient requirements of warmwater, fishes and shellfishes: nutrient requirements of domestics animals. Washington, 1993. 114 p.

OETTERER, M. Industrialização do pescado cultivado. Guaíba: Agropecuária, 2002, 200 p.

- Produção de silagem a partir da biomassa residual de pescado. Alimentos e Nutrição, Araraquara, v. 5, n. 1, p. 119-134, 1994.

OGAWA, M.; MAIA, E. L. Manual de pesca: ciência e tecnologia do pescado. São Paulo: Varela, 1999. 430 p. v. 1.

RAA, M. E. J.; GILBERT, A. Autolysis and proteolytic activity of cod viscera. Journal of Food Technology, New York, v. 11, n. 6, p. 619-28, 1976.

REBECA, D. B.; PEÑA-VERA, M. T.; DÍAZCASTAÑEDA, M. Production of fish protein hidrolysates with bacterial protease, yield and nutritional value. Journal of Food Science, Aquaculture, v. 56, n. 2, p. 2309-14, 1991.
ROSTAGNO, H. S.; ALBINO, L. F. T.; DONZELE, J. L.; GOMES, P. C.; OLIVEIRA, R. F.; LOPES, D. C.; FERREIRA, A. S.; BARRETO, S. L. T. Tabelas brasileiras para aves e suínos - composição de alimentos e exigências nutricionais. Viçosa: Departamento de Zootecnia, 2000. $141 \mathrm{p}$.

SEIBEL, N, F.; SOUZA-SOARES, L.A. Production of chemical silage from marine fish residue. Brazilian Journal of Food Tecnology. São Paulo, v. 6, n. 2, p. 333337, jul./dez. 2003.

SILVA, D. J. Análise de alimentos métodos químicos e biológicos. Viçosa: Imprensa Universitária, 1990. 165 p.

SILVA, N.; JUNQUEIRA, V. C. A.; SILVEIRA, N. F. A. Manual de métodos de análise microbiológica de alimentos. São Paulo: Livraria Valera, 1997.

SOUZA, M. L. R.; MACEDO-VIEGAS, E. M., KRONKA, S. N. Influência do método de filetagem e categorias de peso sobre o rendimento de carcaça, filé e pele de tilápia do Nilo (Oreochromis niloticus). Revista Brasileira de Zootecnia, Viçosa, v. 1, n. 28, p. 1-6, 1999.

TATTERSON, J. N.; WINDSOR, M. L. Fish silage. Journal of the Science of Food and Agriculture, New York, v. 25, n. 1, p. 369-79, 1974.

UCCI, P. Silagem de resíduos de tilápia com adição de diferentes ácidos. 2004. Monografia (Graduação em Engenharia da Pesca) - Centro de Engenharias e Ciências Exatas. Universidade Estadual do Paraná, Toledo.

UNIVERSIDADE FEDERAL DE VIÇOSA. UFV. SAEG Sistema para análises estatísticas e genéticas. Versão 7.1. Viçosa, MG. 1997. 150 p. (Manual do usuário).

VIDOTTI, R. M.; VIEGAS, E. M. M.; CARNEIRO, D. J. Amino acid composition of processed fish silage using different raw materials. Pirassununga: Universidade de São Paulo, 2003. 
